\title{
Transport phenomena in a model cheese: The influence of the charge and shape of solutes on diffusion
}

\author{
J. V. C. Silva, ${ }^{* 1}$ P. D. S. Peixoto, ${ }^{*}$ S. Lortal, ${ }^{*}$ and J. Floury ${ }^{*} \dagger$ \\ *INRA, UMR1253 Science and Technology of Milk and Eggs, F-35042, Rennes, France \\ †Agrocampus Ouest, UMR1253 Science and Technology of Milk and Eggs, F-35042, Rennes, France
}

\begin{abstract}
During cheese ripening, microorganisms grow as immobilized colonies, metabolizing substrates present in the matrix and generating products from enzymatic reactions. Local factors that limit the rates of diffusion, either within the general cheese matrix or near the colonies, may influence the metabolic activity of the bacteria during ripening, affecting the final quality of the cheese. The objective of this study was to determine the diffusion coefficients of solutes as a function of their different physicochemical characteristics (size, charge, and shape) in an ultrafiltrate (UF) model cheese (based on ultrafiltered milk) to enable better understanding of the ripening mechanisms. Diffusion coefficients of fluorescein isothiocyanate (FITC)-dextrans (4 kDa to 2 $\mathrm{MDa})$ and FITC-labeled dairy proteins ( $\alpha$-lactalbumin, $\beta$-lactoglobulin, and BSA) were measured using the technique of fluorescence recovery after photobleaching (FRAP). This study showed that macromolecules up to $2 \mathrm{MDa}$ and proteins could diffuse through the UF model cheese. The larger FITC-dextrans were not more hindered by the structure of the UF model cheese compared with the smaller ones. Any decrease in the diffusion coefficients of solutes was related only to their hydrodynamic radii. The FITC-dextran diffusion data were fitted to an obstruction model, resulting in a constant obstruction factor $(k \sim 0.42)$. Diffusion in the model cheese was sensitive to the physicochemical characteristics of the solute. The FITC-dairy proteins studied (rigid and negatively charged molecules) were hindered to a greater degree than the FITC-dextrans (flexible and charge-neutral molecules) in the UF model cheese. The existence of steric and electrostatic interactions between the protein matrix of the UF model cheese and the FITC-dairy proteins could explain the decrease in diffusion compared with FITC-dextrans.
\end{abstract}

Key words: cheese, diffusion, fluorescence recovery after photobleaching, modeling

Received January 7, 2013.

Accepted July 3, 2013.

${ }^{1}$ Corresponding author: Juliana.ValleCostaSilva@rennes.inra.fr

\section{INTRODUCTION}

The estimation of diffusion coefficients in heterogeneous or homogeneous media is important in various industrial applications (Johansson and Löfroth, 1991). In the food sector, molecular transport characterized by diffusion coefficients is a key feature, especially in dairy processes (Colsenet, 2005). In cheese-making technology, the mass transfer of small solutes (i.e., salt and metabolites) and macromolecules (i.e., nutrients and enzymes) is important in determining microbial and enzyme activities during cheese ripening, a complex process that results in the development of the flavor and texture characteristics of cheese (McSweeney, 2004). Therefore, mass transfer of solutes plays a crucial role in the ripening process and in the final quality of cheese.

During cheese making, bacteria are immobilized within the cheese matrix during the coagulation step. These bacteria grow as colonies in a 3-dimensional spatial distribution. Diffusion is the main mechanism of transferring nutrients around and between the immobilized colonies within the cheese matrix. Substrates have to diffuse across the matrix to reach these bacterial colonies and the metabolites produced have to diffuse from colonies into the protein network (Aly et al., 2011; Jeanson et al., 2011; Floury et al., 2012). Furthermore, after bacterial lysis, enzymes may also diffuse from colonies into the cheese matrix. If enzymes are able to migrate within the matrix, it is important to know the range of their migration around the colonies.

Diffusion properties of solutes in cheese may depend on the composition and microstructure of the matrix, and also on their specific physicochemical characteristics. Floury et al. (2010) have reported a lack of data concerning the diffusion of key molecules involved in cheese ripening. Numerous studies have considered the mass transport of salt and moisture (Morris et al., 1985; Messens et al., 1999; Payne and Morison, 1999; Simal et al., 2001; Pajonk et al., 2003; Bona et al., 2007; Floury et al., 2009). However, fundamental knowledge of the underlying principles of the diffusion of other solutes (e.g., bacterial metabolites, nutrients, and enzymes) in cheese is rarely reported. 
Most of the reported effective diffusion coefficient values of solutes in dairy products such as cheese have been obtained by destructive methods or techniques that are very time-consuming and offer a poor resolution. However, alternative nondestructive techniques, such as nuclear magnetic resonance (NMR) and fluorescence recovery after photobleaching (FRAP), have been developed to measure diffusion coefficients of solutes in both homogeneous and heterogeneous matrices. The NMR technique has been used in a large number of diffusion studies based on relatively simple suspensions and gels. Unfortunately, its application to measure diffusion properties of solutes in more complex media such as cheese is not possible because of the complexity of the spectral data obtained. Moreover, the physical link between the value of the self-diffusion coefficient (the diffusion coefficient of the molecules in the absence of a chemical potential gradient) measured by NMR and the value of the effective diffusion coefficient observed in complex matrices is complex (Floury et al., 2010).

In contrast, FRAP has become a widely used and versatile technique to study diffusion dynamics in various systems, such as living cells, membranes, and other biological environments (Carrero et al., 2003; Seiffert and Oppermann, 2005). In the 1980s and 1990s, the application of the FRAP technique greatly increased with the development of confocal microscopy. However, only recently has this technique been applied to diffusion measurements in food media and it is still unusual (Perry et al., 2006; Carvajal-Rondanelli and Lanier, 2010; Svanberg et al., 2011). Perry et al. (2006) measured the diffusion coefficients of dextrans of various molecular weights in starch solutions over a wide concentration range. More recently, Floury et al. (2012) successfully applied the FRAP technique to measure diffusion properties of small solutes (fluorescein isothiocyanate (FITC)-dextrans of 4 and $20 \mathrm{kDa}$ molecular weights) in a model cheese.

Some researchers have used NMR techniques to explore self-diffusion coefficients of solutes in dairy matrices. Colsenet (2005) and Le Feunteun (2007) measured self-diffusion coefficients of poly(ethylene glycol)s (PEG) in model dairy matrices by pulsed field gradient-NMR. Some studies (Colsenet et al., 2005a,b,c, 2006) showed that PEG diffusion in casein and whey suspensions and gels is affected by protein concentration, the molecular weight of the solute, and rennet coagulation. Le Feunteun and Mariette (2008) studied the self-diffusion of 2 PEG of different molecular sizes (620 and $96,750 \mathrm{~g} / \mathrm{mol}$ ) during the sol-gel transition of a casein system throughout its coagulation process. The effect of the sol-gel transition process on the diffusion behavior of the 2 PEG was dependent on their mo- lecular size; the diffusion coefficient of the small PEG decreased, whereas the diffusion coefficient of the large PEG increased during gel coagulation. They explained these results by the progressive compaction of the casein network caused by gel structural rearrangements with time. Other studies have also shown a great size dependency on solute diffusion in several media, such as polymer, agarose, and poly(vinyl alcohol) aqueous solutions and gels (Masaro et al., 1998; Amsden, 2002; Fatin-Rouge et al., 2004).

The influence of the shape of the solute molecule on their diffusion properties in solutions and gels has also been investigated. Pluen et al. (1999) compared the diffusion properties of different types of macromolecules (e.g., proteins, dextrans, polymer beads, and DNA) with different shapes (linear and globular) with respect to agarose gels. Despite the solutes having the same hydrodynamic radius in solution, the diffusion coefficients of the solutes in the gel were greater for the flexible macromolecules compared with the rigid ones. The difference could be explained by the fact that rigid or spherical macromolecules were more readily trapped in pores compared with the flexible ones. Seiffert and Oppermann (2008) studied the diffusion of linear macromolecules (polyacrylamides) and spherical particles (polystyrene microspheres) across polymer matrices using the FRAP technique. Results showed that the diffusion of flexible molecules remained largely unaffected by the transition from an uncrosslinked solution to a crosslinked network. In contrast, the spherical molecules became completely immobilized when the degree of crosslinking exceeded a particular threshold where the mesh size was comparable to the size of the solute molecule.

Diffusion of solutes in globular dairy protein gels has also been studied using pulsed field gradient-NMR (Croguennoc et al., 2001) and, more recently, FRAP (Balakrishnan et al., 2012). Croguennoc et al. (2001) studied the self-diffusion coefficient of native proteins and dextrans in heat-set globular protein gels. They found that the self-diffusion coefficient of native protein increased after heat treatment because the friction caused by the immobile structure of the gel is much less than that caused by the mobile native proteins. In contrast, they found that the influence of native protein on the self-diffusion coefficient of dextran is small, at least for protein concentrations below 100 $\mathrm{g} / \mathrm{L}$. Balakrishnan et al. (2012) investigated the effects of molecule size and protein and salt concentrations on diffusion of FITC-dextrans in $\beta$-LG solutions and gels. A strong decrease of the diffusion coefficient with increasing molecular size and protein concentration was observed in the most homogeneous gels formed at lower salt concentrations. 
Literature on the influence of the physicochemical characteristics of the solutes on their diffusion properties in dairy products is scarce. The aim of the current study was thus to determine the diffusion coefficients of solute molecules of different physicochemical characteristics in a UF model cheese. This model cheese consisted of a fat-free dairy gel made from a UF retentate. As described previously by Aly et al. (2011), this UF model cheese has a great advantage over traditional cheese technology in that it is formed after renneting without further syneresis of the gel. Moreover, this matrix exhibits highly reproducible micro- and macrostructural properties. Diffusion of the solutes was assessed by FRAP measurements on a confocal laser scanning microscope (CLSM), using a slightly modified version of the protocol and mathematical analysis developed by Floury et al. (2012). Commercial FITC-dextrans of different molecular weights $\left(\mathbf{M}_{\mathrm{W}}\right)$ were chosen as representative examples of flexible solutes, and FITC-dairy proteins of different sizes were chosen for their rigidity and globular shape.

\section{Theoretical Background}

Diffusion across gels (e.g., cheese) may be regarded as a transfer mechanism in a porous matrix, where the pores are connected with each other and filled with an aqueous phase. The diffusive flux $F\left(\mathrm{~kg} \cdot \mathrm{mol} / \mathrm{m}^{2} \cdot \mathrm{s}\right)$ through porous media under steady-state conditions (in a simple 1-dimensional system and uniform temperature and pressure) can be described by Fick's first law:

$$
F=-D_{\text {eff }} \frac{d C}{d x},
$$

where $D_{\text {eff }}$ is the effective diffusion coefficient $\left(\mathrm{m}^{2} / \mathrm{s}\right)$, $C$ is the solute concentration $\left(\mathrm{kg} \cdot \mathrm{mol} / \mathrm{m}^{3}\right)$, and $x$ is the distance $(\mathrm{m})$ traveled by the diffusing molecule. In the model cheese studied, 3 system components may be considered: (1) the protein network, (2) the aqueous phase filling the pores (mainly formed of water, lactose, minerals, and free amino acids), and (3) the diffusing solutes (represented by substrates, metabolites, or enzymes) that are dissolved in the aqueous phase. Between these components, various interactions may take place: obstruction, hydrodynamic drag, changes in the liquid phase properties, and interactions between the protein network and the liquid phase and between the protein network and the solute. A range of theoretical methods has been proposed to describe diffusion processes in various types of gels (Masaro and Zhu, 1999a). Different theoretical approaches have been taken to formulate mathematical models that describe the retardation of solute movement. These models consider different physical concepts such as obstruction effects, hydrodynamic interactions, and free volume effects. It can be assumed that solute diffusion is determined by the probability of the solute molecule finding an opening between the gel strands that is larger than the radius of the solute molecule itself. The gel structure acts like a sieve for solutes, where gel strands obstruct the diffusing molecules (Amsden, 1998a,b). Transport properties also depend on interactions between the solute molecules themselves and between the solute molecules and the surrounding structure, and also on the structure dynamics. In fact, structure dynamics are related to the effect of the movement of the structure itself and its subsequent effect on the diffusion of solutes (Loren et al., 2009). Moreover, the diffusion properties of solutes in gels clearly depend on the volume fraction that is accessible to the diffusing solute in the gel (Babu et al., 2008). No universal theory has yet allowed a sufficiently precise calculation of diffusion coefficients, especially in multi-component food systems such as cheese. Among all the mathematical models available in the literature, the obstruction effect is of practical significance because it can be relatively easily described in mathematical terms (Diaz et al., 1993). In the obstruction model, the matrix acts as a sieve and solutes need to contour obstacles to diffuse. Obstruction effects are related to the increase in the path length for diffusion, the latter characterized by the tortuosity of the matrix. In this case, diffusion is solely inhibited by the structure of the matrix, which is impermeable to the diffusing molecule. If the pores are large compared with the solute size, the mass transfer of the solute within the aqueous phase contained in the pores of the matrix can be described by Fick's diffusion model. In such case, the flux must be described in terms of an "effective" diffusion coefficient $\left(\boldsymbol{D}_{\text {eff }} ; \mathrm{m}^{2} / \mathrm{s}\right)$, defined as

$$
D_{\text {eff }}=k D_{\text {aq }} \text {, }
$$

where $D_{\text {aq }}$ is the diffusion coefficient in the aqueous phase $\left(\mathrm{m}^{2} / \mathrm{s}\right)$ and $k$ is an obstruction factor generated by the matrix. This obstruction factor is a function of structural parameters, as the porosity of the matrix $(\varepsilon)$, related to the available volume accessible for the diffusion, and the tortuosity of the matrix $(\tau)$ (Welti-Chanes et al., 2003). In the current study, low solute concentrations were used to ensure that interaction between the diffusing solutes could be neglected. Assuming that these solutes have a dynamic behavior similar to the random movement of particles in solution (e.g., aqueous phase), and in the absence of any interactions with other solutes present, the diffusion process is controlled 
by the size of the solute molecule as described by the Stokes-Einstein equation:

$$
D_{\text {aq }}=\frac{k_{B} T}{6 \pi \mu R_{\mathrm{h}}},
$$

where $k_{B}$ is the Boltzmann constant $\left(1.38 \times 10^{-23} \mathrm{~J} /\right.$ mol K), $T$ is the absolute temperature $(\mathrm{K}), \mu$ is the viscosity of the solution $(\mathrm{Pa} \cdot \mathrm{s})$, and $R_{\mathrm{h}}$ is the hydrodynamic radius $(\mathrm{m})$ of the diffusing molecule. However, this equation is not adapted to describe the diffusion of solutes in concentrated systems. In concentrated systems, diffusion phenomena are explained by different models essentially linked to the nature of the diffusing solute (i.e., flexible or rigid). Although the hydrodynamic radius is the defining parameter for rigid solutes, the usual parameter to describe diffusion for flexible solutes is molecular weight. A simple power law gives a description of the diffusion coefficient $(D)$ as a function of the solute $\mathrm{M}_{\mathrm{W}}$ (Eq. [4]),

$$
D=A M_{W}^{-\alpha},
$$

where $A$ is a pre-exponential factor constant and $\alpha$ is a characteristic exponent. This type of relation is often proposed to describe the diffusion behavior of macromolecules in different media, with $\alpha$ values increasing for more elongated shapes. The $\alpha$ values range between 0.5 and 0.6 for diffusion in dilute systems (de Gennes, 1979) up to 2.5 for diffusion in concentrated systems (Tao et al., 2000).

\section{MATERIALS AND METHODS}

\section{Fluorescent Solutes}

Fluorescein isothiocyanate conjugate tagged dextrans (FITC-dextrans) of 8 different $\mathrm{M}_{\mathrm{W}}$ (Table 1) were purchased from Sigma-Aldrich (St. Louis, MO) and referred to as FITC-D4, FITC-D10, FITC-D20, FITCD40, FITC-D70, FITC-D250, FITC-D500, and FITCD2000, according to their nominal average $\mathrm{M}_{\mathrm{W}}$ (where $4=4 \mathrm{kDa}$ and $2000=2 \mathrm{MDa}$ ). The FITC-dextrans were chosen because they are prone to photobleaching, are commercially available across a wide range of sizes, and because the excitation and emission of FITC (488 and $512 \mathrm{~nm}$, respectively) are ideally suited to the sapphire laser of the confocal microscope used. Free FITC and FITC-BSA were also purchased from Sigma-Aldrich. The 2 proteins $\alpha-\mathrm{LA}$ and $\beta$-LG (INRA, Rennes, France) were labeled using free FITC. These proteins were dissolved at a concentration of $0.27 \mathrm{~m} M$ in a 10 $\mathrm{m} M$ phosphate buffer solution ( $\mathrm{pH} 8.0$ ). They were covalently labeled with FITC by mixing $1.8 \mathrm{~mL}$ of a FITC solution ( $38 \mathrm{~m} M$ FITC) with $100 \mathrm{~mL}$ of the protein solution for 90 min at $19^{\circ} \mathrm{C}$ and protected from light. The solutions of FITC- $\alpha$-LA and FITC- $\beta$-LG were then dialyzed with cellulose membranes (6-8 kDa cut-off; Spectrum Laboratories Inc., Rancho Dominguez, CA) against $10 \mathrm{~m} M$ Tris, $0.6 \mathrm{M} \mathrm{NaCl}$ buffer (pH 7.33) for 2 $\mathrm{d}$ to eliminate any free FITC molecules. A final dialysis was made using deionized water. Subsequently, the 2 solutions were lyophilized and reaction rate efficiencies were analyzed by mass spectroscopy (QSTAR XL, Applied Biosystems, Concord, ON, Canada). About 33\% of the proteins were mono-labeled, and $5 \%$ and $1 \%$ were di-labeled with FITC for $\alpha$-LA and $\beta$-LG, respectively. For the FRAP experiments, the FITC-dextrans, FITC$\alpha-\mathrm{LA}$, and FITC- $\beta$-LG were dissolved to $50 \mathrm{mg} / \mathrm{mL}$ in water. For FITC-BSA, the solution was prepared by dissolving the fluorescent solute to $25 \mathrm{mg} / \mathrm{mL}$ in a 0.1 $M$ BisTris buffer at $\mathrm{pH}$ 6.8. These aqueous solutions were stored at $-20^{\circ} \mathrm{C}$ and protected from light before and during fluorescence measurements.

\section{UF Model Cheese Production}

Preparation of the Retentate by UF of Milk. The UF milk retentate was produced following a previously described procedure (Ulve et al., 2008), except that neither $\mathrm{NaCl}$ nor cream was added, giving a nonsalty and a nonfatty retentate. The total proteins in the milk were concentrated by a factor of 5 and the concentration of the final retentate $(\mathrm{pH} \mathrm{6.6)} \mathrm{obtained}$ was as follows: DM, $223 \mathrm{~g} / \mathrm{kg}$, total $\mathrm{N}, 159.7 \mathrm{~g} / \mathrm{kg}$, NCN, $29 \mathrm{~g} / \mathrm{kg}$, and NPN, $1.8 \mathrm{~g} / \mathrm{kg}$. The final composition of the UF permeate (or ultrafiltrate), filtered on a $0.2-\mu \mathrm{m}$ filter (Nalgene Labware, Thermo Fisher Scientific, Roskilde, Denmark) was as follows: DM, 55.3 $\mathrm{g} / \mathrm{kg}$, total $\mathrm{N}, 2 \mathrm{~g} / \mathrm{kg}$, and NPN of $1.6 \mathrm{~g} / \mathrm{kg}$. The UF milk retentate obtained was stored at $-20^{\circ} \mathrm{C}$ in sterile plastic bottles, whereas the ultrafiltrate was stored at $4^{\circ} \mathrm{C}$ in sterile glass flasks.

UF Model Cheese Manufacture. The model cheese-making protocol used in the manufacture of the UF model cheese was as described by Aly et al. (2011). The retentate was heated at $93^{\circ} \mathrm{C}$ for 15 min and then cooled for 3 min using melting ice. This heat treatment cycle enabled the avoidance of syneresis in the model cheese during the subsequent diffusion experiments by increasing the capacity of the formed protein network to retain water (Ferron-Baumy et al., 1991; Vaziri et al., 2010). Sodium azide was added to the retentate at a final concentration of $0.05 \%$ (wt/wt) to avoid microorganism growth. The coagulant agent Maxiren 180 
Table 1. Molecular weights $\left(\mathrm{M}_{\mathrm{W}}\right)$ and diffusion coefficients in water $\left(D_{\text {water }}\right)$ for the 2 solutes, fluorescein isothiocyanate (FITC)-dextrans (D4 to D2000) and FITC-dairy proteins, at $19^{\circ} \mathrm{C}$ and their corresponding hydrodynamic radii (calculated $R_{\mathrm{h}}$ ) and those from the literature (nominal $R_{\mathrm{h}}$ )

\begin{tabular}{|c|c|c|c|c|c|}
\hline Solute & $\begin{array}{c}\mathrm{M}_{\mathrm{W}} \\
(\mathrm{kDa})\end{array}$ & $\begin{array}{c}D_{\text {water }}^{1} \\
\left(\mu \mathrm{m}^{2} / \mathrm{s}\right)\end{array}$ & \multicolumn{2}{|c|}{$R_{\mathrm{h}}(\mathrm{nm})$} & Reference \\
\hline \multirow{3}{*}{ FITC-D10 } & 10 & $66 \pm 2.2$ & $3.2 \pm 0.1$ & 2.3 & Sigma-Aldrich \\
\hline & & & & 2.7 & Prausnitz and Noonan, 1998 \\
\hline & & & & $2.86-5.12$ & Hagman et al., 2010 \\
\hline FITC-D20 & 20 & $44 \pm 2.6$ & $4.9 \pm 0.3$ & 3.2 & Nugent and Jain, 1984 \\
\hline \multirow{3}{*}{ FITC-D40 } & & & & 4.62 & Nugent and Jain, 1984 \\
\hline & & & & 5.0 & Prausnitz and Noonan, 1998 \\
\hline & & & & 5.5 & Balakrishnan et al., 2012 \\
\hline \multirow[t]{4}{*}{ FITC-D70 } & 70 & $33 \pm 1.7$ & $6.5 \pm 0.2$ & 5.79 & Nugent and Jain, 1984 \\
\hline & & & & 6.0 & Sigma-Aldrich \\
\hline & & & & 6.4 & Prausnitz and Noonan, 1998 \\
\hline & & & & 7.4 & Lebrun and Junter, 1993 \\
\hline \multirow{2}{*}{ FITC-D2000 } & & & & $\begin{array}{l}27.0 \\
27.2\end{array}$ & $\begin{array}{l}\text { IdB Consultancy } \\
\text { Lebrun and Junter, } 1993\end{array}$ \\
\hline & & & & $\begin{array}{l}27.2 \\
50.0\end{array}$ & Balakrishnan et al., 2012 \\
\hline \multirow[t]{2}{*}{ FITC- $\alpha-L A$} & 14 & $102 \pm 7.3$ & $2.09 \pm 0.1$ & 1.90 & Saltzman et al., 1994 \\
\hline & & & & 2.12 & Johnson et al., 1996 \\
\hline FITC- $\beta$-LG & 18 & $85 \pm 5.4$ & $2.50 \pm 0.1$ & 2.6 & Beretta et al., 2000 \\
\hline \multirow[t]{4}{*}{ FITC-BSA } & 66 & $59 \pm 8.6$ & $3.65 \pm 0.5$ & 3.5 & Sigma-Aldrich \\
\hline & & & & 3.55 & Nugent and Jain, 1984 \\
\hline & & & & 3.59 & Johnson et al., 1996 \\
\hline & & & & 3.93 & Pluen et al., 1999 \\
\hline
\end{tabular}

${ }^{1}$ Diffusion coefficient in water at $19^{\circ} \mathrm{C}$ determined by fluorescence recovery after photobleaching. Diffusion coefficients are given as mean $\pm \mathrm{SD}$ for 10 measurements.

${ }^{2}$ Hydrodynamic radius of solutes calculated from the Stokes-Einstein equation (Eq. [3]).

${ }^{3}$ Data from the literature or from supplier data (extracted from diffusion data obtained by various methods); Sigma-Aldrich, St. Louis, MO; TdB Consultancy, Uppsala, Sweden.

${ }^{4}$ This value was extrapolated from the radius values reported in supplier's data according to the power law $R_{\mathrm{h}}=0.7734 \mathrm{M}_{\mathrm{W}}^{0.4735}$.

(DSM Food Specialties, Seclin, France) was added to the heat-treated retentate, to give a final concentration of $0.03 \%$ ( $\mathrm{vol} / \mathrm{vol})$. At this point, the FITC-labeled molecules (the solutions prepared previously) were added, giving a final concentration of $0.50 \mathrm{mg} / \mathrm{mL}$ in each case, except for the FITC-BSA, which had a final concentration of $0.25 \mathrm{mg} / \mathrm{mL}$.

Gel Cassette Preparation. The use of the gel cassette system (Brocklehurst et al., 1995, 1996) enabled nondestructive and microscopic examinations. The gel cassette comprised an acetal frame $(37 \times 25 \mathrm{~mm}, 2 \mathrm{~mm}$ thick) sealed within a glass cover slide and a coverslip with an adhesive Gene Frame (ABgene, Epsom, UK). The gel cassette was filled with $1 \mathrm{~mL}$ of the previously prepared mixture (i.e., the retentate + the coagulant agent + the FITC-labeled molecule). Before microscopic observations, the gel cassette was incubated at $30^{\circ} \mathrm{C}$ for $1 \mathrm{~h}$ to enable coagulation of the retentate and then held at $19^{\circ} \mathrm{C}$ for $2 \mathrm{~h}$.

\section{FRAP Protocol and Analysis}

The FRAP experiments were carried out using an inverted CLSM (Nikon, Champigny-sur-Marne, France). The samples were observed using a $40 \times$ objective lens (oil immersion) with a numerical aperture of 1.30. The measurements were directly recorded at a constant depth of $15 \mu \mathrm{m}$ from the coverslip. The FITC-labeled molecules were excited using a $50 \mathrm{~mW}$ sapphire laser system at a wavelength of $488 \mathrm{~nm}$ and detected on a 500 to $530 \mathrm{~nm}$ spectral bandwidth. All experiments were performed at $19^{\circ} \mathrm{C}$ in an air-conditioned room to avoid any temperature effect on diffusion coefficient values. Fluorescence intensity image size was fixed to $256 \times$ 256 pixels with a $1.24-\mu \mathrm{m}$ pixel size. Before bleaching, 3 images were scanned to record the prebleach fluorescence intensity. These images were acquired at $0.1 \%$ of the maximum laser intensity. For bleaching, a small circular region of interest $(\mathbf{R O I})$ with radius $5.2 \mu \mathrm{m}\left(\boldsymbol{w}_{B}\right)$ 
was used, in which 5 images were scanned at $100 \%$ laser intensity. After bleaching, 50 to 200 single-section images (depending on the solute size) were collected to monitor the recovery process. The first image was acquired $2.5 \mathrm{~s}$ after the beginning of bleaching. The laser power was restored to its initial value $(0.1 \%$ of the bleach intensity) for imaging after photobleaching. The FRAP experiments were also carried out in the same conditions in water (or in a $0.1 \mathrm{M}$ BisTris buffer $\mathrm{pH} 6.8$ for BSA), and in ultrafiltrate with the FITC-labeled molecules. About $100 \mu \mathrm{L}$ of the fluorescent water or ultrafiltrate was poured between a glass slide and a coverslip sealed with an adhesive frame (Gene Frame, ABgene). Between 5 and 10 repetitions of the FRAP experiments were done on each sample. Then, results were separately modeled to obtain a reliable average diffusion coefficient of the FITC-labeled molecules in each medium and to test the repeatability of the method. Two different sets of UF cheeses were prepared to test the reproducibility of the FRAP experiments.

\section{Data Analysis}

The assumptions made were a pure isotropic diffusion in a homogeneous medium and a 2-dimensional diffusion process, as made in previously reported work (Blonk and Vanaalst, 1993; Braeckmans et al., 2003; Braga et al., 2004; Waharte et al., 2010; Floury et al., 2012). Therefore, by assuming diffusion as the only relevant transport process and assuming a homogeneous medium, the system behaves according to the classical diffusion equation after photobleaching:

$$
\frac{\partial}{\partial t} C(\vec{r}, t)=D \Delta^{2} C(\vec{r}, t)
$$

where $C(\vec{r}, t)$ is the concentration of the solutes at position $\vec{r}$ at time $t$. Most FRAP models assume that diffusion during bleaching is negligible (Axelrod et al., 1976; Braeckmans et al., 2003). However, small solute molecules are generally very mobile. The diffusion of these solutes will have already started during the bleach phase and the following time lag before the first image is taken. Therefore, data collected were analyzed using the model proposed by Braga et al. (2004) that enables the diffusion of molecules to be taken into account during this initial period. The parameters $K_{M}$ and $w_{M}$ were estimated by fitting Eq. [6] to the experimental data using the function nls in $\mathrm{R}$ software (version 2.14.1, The R Foundation for Statistical Computing, Vienna, Austria):

$$
F_{M}(r, 0)=F_{0} \exp \left[-K_{M} \exp \left(-2 \frac{r^{2}}{w_{M}^{2}}\right)\right],
$$

where $F_{0}$ is the fluorescence intensity before bleaching, $F_{M}$ is the mobile fraction fluorescence, $K_{M}$ is the bleach efficiency for the mobile molecule (the coordinate's origin is the center of the bleached region), and $w_{M}$ is the profile width $(\mathrm{m})$ in the radial direction. These parameters are dependent on the diffusion coefficient of the solutes. According to Eq. [6], normalized fluorescence recovery inside a region of radius $w_{B}$ is given by Braga et al. (2004):

$$
\begin{aligned}
& F_{M}^{2 D}(t)= \\
& \frac{F_{0}}{2}\left\{\frac{w_{M}^{2}}{w_{B}^{2}}\left[\sum_{n=1}^{+\infty} \frac{\left(-K_{M}\right)^{n}}{n ! n}\left[1-\exp \left\{\frac{-2 n}{1+2 n \frac{t}{\tau_{D}}} \frac{w_{B}^{2}}{w_{M}^{2}}\right]\right)\right]+2\right\}
\end{aligned}
$$

where $\tau_{D}$ is the characteristic time of diffusion.

The FRAP recovery curves were normalized to take into account the loss of fluorescence caused by imaging. This loss of fluorescence intensity with time was measured for a background region $(\boldsymbol{B} \boldsymbol{G})$ remote from the ROI and calculated as follows:

$$
B G^{\prime}(t)=B G(t)-B G(i)
$$

where $B G(i)$ is the fluorescence in background region before bleaching. The normalized fluorescence recovery inside the ROI was calculated by subtracting the BG fluorescence intensity from the average fluorescence in the photobleached region $I(t)$ :

$$
F_{M}^{2 D}(t)=\frac{I(t)-B G^{\prime}(t)}{I_{i}}
$$

where $I_{i}$ is the fluorescence in the bleached region before bleaching. The FRAP recovery curves were fitted with Eq. [7] $(n=100)$ using the function $n l s$ to obtain the characteristic time of diffusion $\left(\tau_{D}\right)$. Finally, the $D_{\text {eff }}$ of the migrating solute was calculated using the following equation:

$$
D_{\text {eff }}=\frac{w_{M}^{2}}{4 \tau_{D}} .
$$

Analysis of the recorded images was performed by the EZ-C1 FreeViewer software, Gold Version 3.2, Nikon Corp. 


\section{RESULTS AND DISCUSSION}

\section{FRAP Data Analysis}

The results of some typical FRAP experiments looking at the diffusion of FITC- $\alpha-\mathrm{LA}$ in the UF model cheese are presented in Figure 1. Figure 1a shows a typical image sequence obtained over time during a FRAP experiment. Figure 1b summarizes 10 fluorescence recovery curves obtained on the same sample. In Figure $1 \mathrm{~b}$, the larger graph represents recovery curves before taking into account the loss of fluorescence intensity, in which fluorescence intensity decreased over time. The smaller graph shows recovery curves after correction. Figure 1c shows a typical corresponding recovery curve of fluorescence as measured (dots) and from the model (line) as a function of time (left panel). A histogram of diffusion coefficient values for 10 measurements on the same sample is also presented (right panel). The left graph shows the good fit of the experimental data with the Braga model used in this study. The histogram demonstrates the good repeatability of the FRAP method. These results serve to validate the FRAP data acquisition and subsequent analysis.

\section{Experimental Validation of FRAP Method}

Diffusion of FITC-Dextrans and FITC-Dairy Proteins in Water. To validate the FRAP protocol, experimental diffusion coefficients of solutes (FITCdextrans and FITC-dairy proteins) were measured in water or in a buffered solution. Table 1 sets out the experimental diffusion coefficient values of solutes in water at $19^{\circ} \mathrm{C}\left(\boldsymbol{D}_{\text {water }}\right)$. The effective hydrodynamic radius $\left(R_{\mathrm{h}}\right)$ of each solute molecule was calculated from the Stokes-Einstein relation (Eq. [3]) and are given in Table 1 . These effective hydrodynamic radii were compared with data from the literature or from supplier data (Table 1) extracted from diffusion data obtained by various methods (dynamic light scattering, fluorescence imaging of concentration profiles, or FRAP). The hydrodynamic radii obtained for the solutes (calculated $R_{\mathrm{h}}$ in Table 1 ) were very similar to typical values reported previously (nominal $R_{\mathrm{h}}$ in Table 1). These results allowed the validation of the FRAP protocol used in this study, as previously described by Floury et al. (2012).

Diffusion of FITC-Dextrans and FITC-Dairy Proteins in Ultrafiltrate. The ultrafiltrate composition was similar to the aqueous phase filling the pores of the UF model cheese. Experimental diffusion coefficients of solutes (FITC-dextrans and FITC-dairy proteins) were measured in ultrafiltrate $\left(D_{\text {aq }}\right)$ using the FRAP technique. These experimental values were compared with diffusion coefficients estimated by using the Stokes-Einstein equation (Eq. [3]), using the effective hydrodynamic radii of solutes provided in Table 1 (calculated from $D_{\text {water }}$ ), and the viscosity of the ultrafiltrate $\left(1.2 \mathrm{mPa} \cdot \mathrm{s}\right.$ at $19^{\circ} \mathrm{C}$, according to Guinee, 2004). With the exception of FITC-D500, experimental diffusion coefficient values for the FITC-dextrans in the ultrafiltrate were in good agreement with the calculated diffusion coefficients (Figure 2). The similarity between the measured and the calculated diffusion coefficients in the ultrafiltrate showed that interactions between solutes and ultrafiltrate components (e.g., lactose, minerals) could be negligible, as already suggested by Floury et al. (2012). Logarithmic plots of the experimental diffusion coefficients obtained for FITC-dextrans in the ultrafiltrate as a function of their molecular weights are presented in Figure 2. This relationship is in agreement with the classical Stokes-Einstein relation (Eq. [3]) and with Flory's scaling law for a linear or randomly branched chain in a good solvent at infinite dilution (Flory, 1953). For the FITC-dairy proteins, experimental diffusion coefficients in the ultrafiltrate were also in agreement with the calculated diffusion coefficient values. The values obtained for $D_{\mathrm{aq}}$ were 82 $\pm 7.9,79 \pm 4.2$ and $41 \pm 4.7 \mu^{2} / \mathrm{s}$ (experimental values) for FITC- $\alpha$-LA, FITC- $\beta-L G$, and FITC-BSA, compared with the calculated values of $85 \pm 6.1,71$ \pm 4.5 , and $49 \pm 7.2 \mu \mathrm{m}^{2} / \mathrm{s}$, respectively. These results further validated the FRAP method used in this study.

\section{Diffusion in the Model Cheese}

Diffusion of FITC-Dextrans. Effective diffusion coefficients $\left(D_{\text {eff }}\right)$ are the most convenient way to represent the diffusion process through porous matrices because the diffusing solute molecules might take a tortuous path as they pass through (Varzakas et al., 2005). Effective diffusion coefficients of the FITC-dextrans were measured in the UF model cheese. The relationship between $D_{\text {eff }}$ in the UF model cheese and the $\mathrm{M}_{\mathrm{W}}$ of the FITC-dextrans is illustrated in Figure 2. A decrease of the diffusion coefficient with increasing $\mathrm{M}_{\mathrm{W}}$ of the solute was observed for the FITC-dextrans, as observed in previous studies on the diffusion of various solutes through dairy matrices (Colsenet, 2005; Le Feunteun, 2007; Balakrishnan et al., 2012; Floury et al., 2012). Diffusion coefficient values of FITC-dextrans in the UF model cheese were much smaller than those in the aqueous phase (i.e., in the ultrafiltrate solution; Figure 2 ), due to the hindrance of the protein network present. As for the ultrafiltrate, logarithmic plots of the experimental diffusion coefficients of the FITC-dextrans as a function of their $\mathrm{M}_{\mathrm{W}}$ in the UF model cheese followed a linear relationship with a slope very close to -0.5 . 
a)

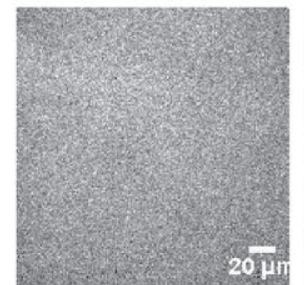

Prebleach

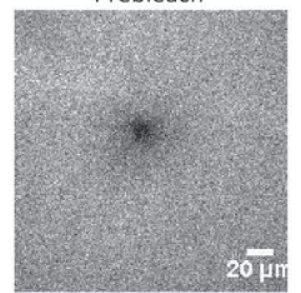

$\mathrm{R} 10: \mathrm{t}=4.705 \mathrm{~s}$

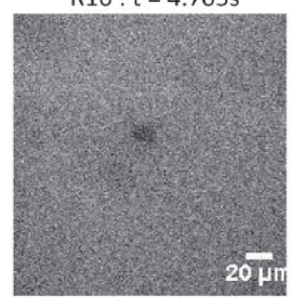

$R 50: t=24.213 s$

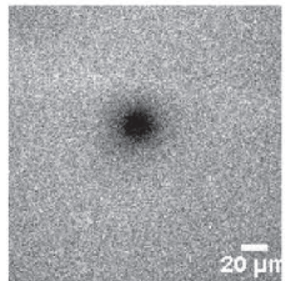

$\mathrm{R} 1: \mathrm{t}=0 \mathrm{~s}$

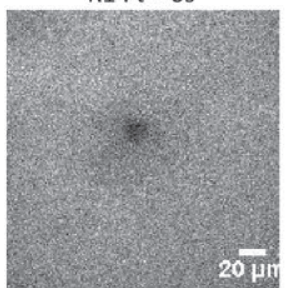

$R 20: t=9.584 s$

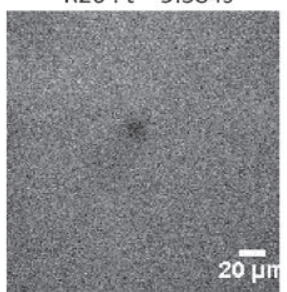

$R 60: t=29.088 s$

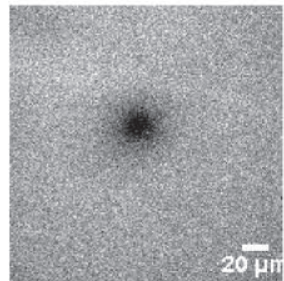

$R 3: t=1.283 \mathrm{~s}$

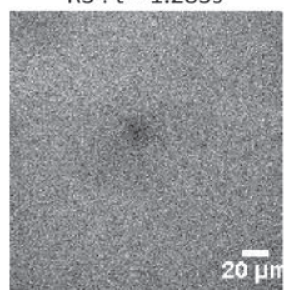

$\mathrm{R} 30: \mathrm{t}=14.447 \mathrm{~s}$

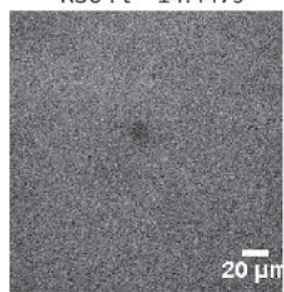

$R 80: t=38.858 s$

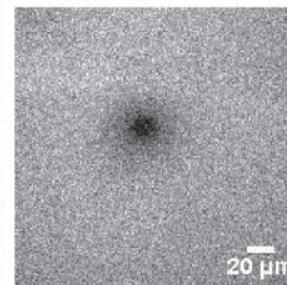

$R 5: t=2.26 s$

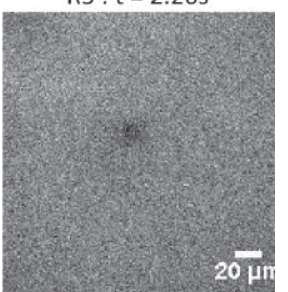

$R 40: t=19.33 s$

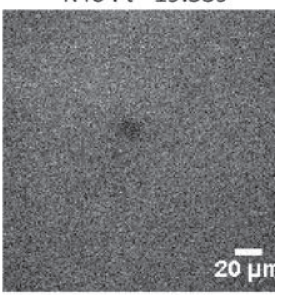

$R 100: t=48.62 s$

b)

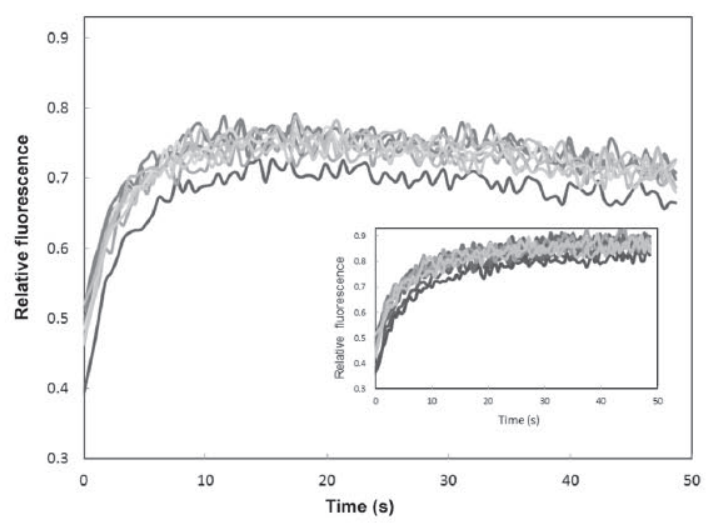

c)
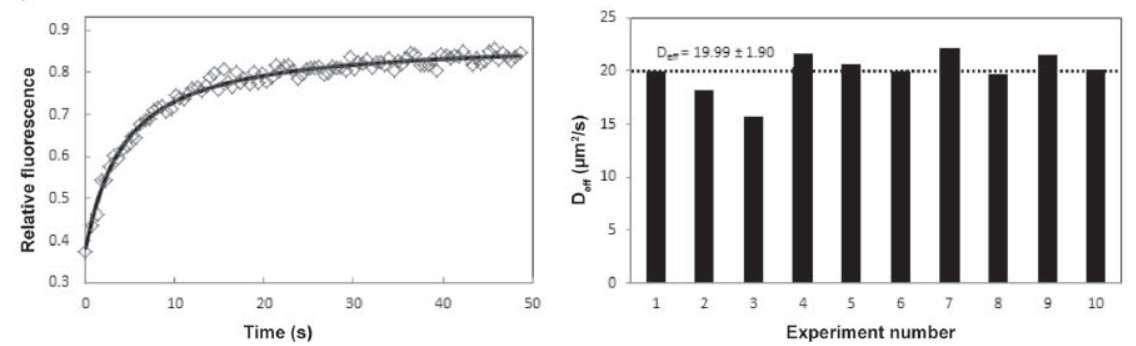

Figure 1. Determination of diffusion coefficients by fluorescence recovery after photobleaching (FRAP). Example of fluorescein isothiocyanate (FITC)- $\alpha$-LA diffusing in the UF model cheese. (a) Typical image sequence [a prebleach and some recovery (R) images] obtained with time (t) during a photobleaching experiment; (b) summary of the 10 fluorescence recovery curves obtained on the same sample, before (larger image) and after (smaller image) accounting for the loss of fluorescence intensity; (c) typical corresponding recovery curve of fluorescence as measured (dots) and from the model (line) as a function of time (left image), and representation of the dispersion of estimated diffusion coefficients for 10 measurements on the same sample (right image). $D_{\text {eff }}=$ effective diffusion coefficient. 


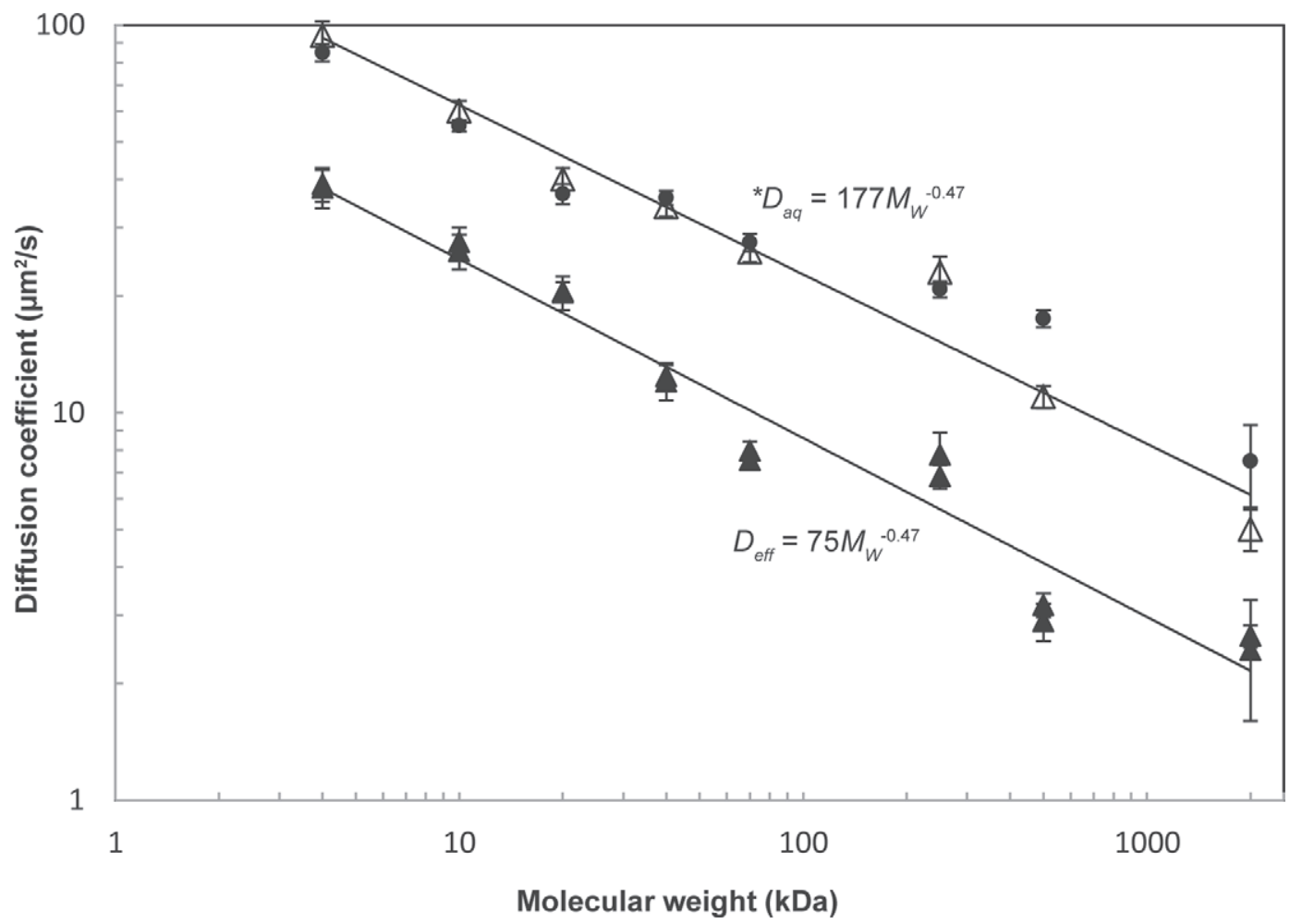

Figure 2. Logarithmic plots of experimental diffusion coefficients of fluorescein isothiocyanate (FITC)-dextrans in the UF model cheese (ム) and in the ultrafiltrate (aqueous phase) $(\Delta)$ as a function of their molecular weight. Logarithmic plots of diffusion coefficients for the FITCdextrans in the ultrafiltrate (estimated from the Stokes-Einstein equation using the effective hydrodynamic radii obtained in water) as a function of their molecular weight $\left(\mathrm{M}_{\mathrm{W}}\right)(\bullet)$. The solid lines correspond to the best fit to a power law. $D_{\text {eff }}=$ effective diffusion coefficient; $D_{\text {aq }}=$ diffusion coefficient in the aqueous phase.

An $\alpha$ value of 0.47 was found for these solutes in the ultrafiltrate, as well in the UF model cheese (Figure 2). This observation implies that in the UF model cheese, the larger solute molecules were not more hindered by the structure of the matrix compared with the smaller ones. The same diffusion behavior was not observed previously for the diffusion of FITC-dextrans in a chitosan matrix (1.5 wt\%; Payet et al., 2008). They found an $\alpha$ value close to 1 for the smaller solute molecules (FITC-D4 and FITC-D70). They also observed that the diffusion of the larger solutes investigated (FITC-D150 and FITC-D250) were substantially slowed because of cross-linking in the gel even though their hydrodynamic radius was relatively small $\left(R_{\mathrm{h}}=4.8 \pm 0.5\right.$ and 6.0 \pm 0.5 , respectively) compared with the mesh size of the chitosan matrix $(54.9 \pm 4.4 \mathrm{~nm}$ at $\mathrm{pH} 5)$. Payet et al. (2008) hypothesized the existence of specific interactions between these larger solutes and the gel. Colsenet et al. (2006) found an $\alpha$ value varying between 0.59 and 0.84 for the self-diffusion of PEG of different molecular weights $(1,080,8,500$, and $82,250 \mathrm{~g} / \mathrm{mol})$ in whey protein gels (for whey protein concentrations between 0.1 and $0.4 \mathrm{~g} / \mathrm{g}$ ), higher $\alpha$ values compared with the UF model cheese studied in the current study (with a protein concentration of $0.16 \mathrm{~g} / \mathrm{g}$ ). Solutes are known to be more hindered in a whey network than in a casein network with the same protein concentration (Colsenet et al., 2005b, 2006). In the current study, the UF model cheese was not concentrated enough to induce a reptation-like diffusion behavior for the FITCdextrans, as previously observed for PEG diffusion in other types of gels (Favre et al., 2001; Colsenet et al., 2006). They concluded that these gel networks were not dense enough to induce the reptation mechanism, but dense enough so that the solute conformations corresponding to elongated shapes are favored for the diffusion step to be effective. However, for the UF model cheese (with an a close to 0.5), the assumption can be made that the FITC-dextrans could easily diffuse through the pores of the matrix without being forced to adopt a more elongated shape, at least in an overall manner, behaving rather as random spherical coils. Indeed, the degree of obstruction might depend on the size of the pores in the matrix compared with the size of the diffusing molecule (Hermansson et al., 2006; Cai et al., 2011). Given that all the FITC-dextrans (from 4 $\mathrm{kDa}$ to $2 \mathrm{MDa}$ ) presented the same diffusion behavior in the model cheese, the pore sizes of the gel must be 
much larger than the maximum diameter of the solutes studied (i.e., a diameter of $50 \mathrm{~nm}$ for FITC-D2000), as hypothesized in the obstruction model described by Eq. [2]. This same equation correlates $D_{\text {eff }}$ in the matrix with $D_{\text {aq }}$ (i.e., ultrafiltrate) as a function of structural parameters (e.g., porosity, tortuosity). The effective diffusion coefficients of FITC-dextrans in the UF cheese were proportional to their respective diffusion properties in the aqueous phase, with $D_{\text {eff: }} D_{\text {aq }}$ of approximately 0.42 (Figure 3 ). The implication is that the mobility of FITC-dextrans in the UF model cheese was reduced by a constant obstruction factor $(k \sim 0.42)$. It is very important to bear in mind that the obstruction model principle presupposes that the protein network of the UF model cheese is "fixed." Moreover, this model does not take into account either solute-matrix interactions or the physicochemical properties of the solutes, which have been found to be significant in certain cases (Matsukawa and Ando, 1997; Masaro and Zhu, 1999b). We assumed there were no electrostatic interactions between the FITC-dextrans and the UF model cheese because these solutes are molecules with a neutral charge. Furthermore, protein aggregates of the UF model cheese must be hypothesized as forming "impermeable segments" immersed in the aqueous phase. This implies that diffusion phenomenon of solutes through protein aggregates must be negligible. However, various studies have been discussed on the porosity of casein micelles (McMahon and Oommen, 2008; Bouchoux et al., 2010). Some published results concerning diffusion phenomena in casein suspensions and gels are consistent with such hypotheses. Colsenet et al. (2005b) and Le Feunteun and Mariette (2008) studied the effect of casein concentration on diffusion of PEG molecules in suspensions and gels. They hypothesized that the obstruction effect for the PEG molecules could be presented as 2 diffusion pathways: one around the micelle particles and one through the micelle particles. Le Feunteun and Mariette (2008) used the cell model developed by Jönsson et al. (1986) to interpret self-diffusion of small and large PEG (620 and $96,750 \mathrm{~g} / \mathrm{mol}$ ) during sol-gel transition in casein systems. They observed that the diffusion of the larger PEG $(96,750 \mathrm{~g} / \mathrm{mol})$ was not affected by the sol-gel transition but was closely related to the progressive increase in the porosity of the gel. Le Feunteun and Mariette (2008) observed, on the other hand, a small decrease in the diffusion rate of the smaller PEG $(620 \mathrm{~g} / \mathrm{mol})$ progressively after approximately $5 \mathrm{~h}$. They explained that the differences between the free volume fractions in the matrix (which are accessible to the molecules investigated), would account for different amounts of accessible space inside the casein particles. Nevertheless, in the present study, based on the conclusion that a similar diffusion behavior was found for FITC-dextrans across a wide range of $\mathrm{M}_{\mathrm{W}}$ (4 $\mathrm{kDa}$ to $2 \mathrm{MDa}$ ), it was assumed that diffusion of these solutes through protein aggregates of the UF model cheese could be neglected. We observed that even if the FITC-dextrans were able to diffuse through the protein aggregates of the UF model cheese, the overall diffusion was not significantly affected by this diffusion pathway.

Diffusion of FITC-Dairy Proteins. To study the influence of different physicochemical characteristics of solutes (e.g., size, shape, and charge) on their diffusion in the UF model cheese, experimental diffusion coefficients of 3 FITC-labeled dairy proteins ( $\alpha$-LA, $\beta-\mathrm{LG}$, and BSA) were also measured using the FRAP technique. As an example, Figure 1 shows some FRAP curves obtained for FITC- $\alpha$-LA diffusing through the UF model cheese. In this same cheese, FITC-labeled dairy proteins did not exhibit the same diffusion behavior compared with the FITC-dextrans. As shown in Figure 4, a sharp decrease of the diffusion coefficients was observed for the FITC-dairy proteins compared with the FITC-dextrans with similar hydrodynamic radii. Rigid and negatively charged molecules (i.e., the FITC-dairy proteins) were thus more hindered by the matrix than the flexible and neutral molecules (i.e., the FITC-dextrans), suggesting the existence of interaction phenomena between the matrix and these proteins. The hindered diffusion of proteins compared with dextrans could be caused by electrostatic, chemical, or steric factors. The electric charge of diffusing protein molecules in the UF model cheese is an important physicochemical characteristic that might influence their effective diffusion coefficients in the matrix if electrochemical interactions exist. The isoelectric points of $\alpha-L A$, $\beta-\mathrm{LG}$, and BSA are 4.8, 5.3, and 5.1, respectively (Kinsella and Whitehead, 1989). These proteins were then negatively charged at the $\mathrm{pH}$ of the matrix (6.6). At the same $\mathrm{pH}$, the overall charge of the casein micelles forming the protein network of the gel is also negative, limiting the possibility of solute-matrix interactions by electrochemical bonds. We then hypothesized that attractive electrostatic interactions between the matrix and these proteins were negligible. Electrostatic interactions would be expected to yield repulsive forces between the diffusing protein molecules (negatively charged at 6.6) and the negatively charged matrix. Repulsive forces could cause a decrease in diffusion of the proteins in the UF model cheese. Moreover, it appeared that the molecular geometry of the proteins (i.e., their shape) must also have affected their diffusion in the UF model cheese. Indeed, some authors (Pluen et al., 1999; Seiffert and Oppermann, 2008) report that diffusion processes in porous gels are fundamentally different for different kinds of solute molecules. The drag retarding the movement of the rigid and spherical solutes (i.e., 


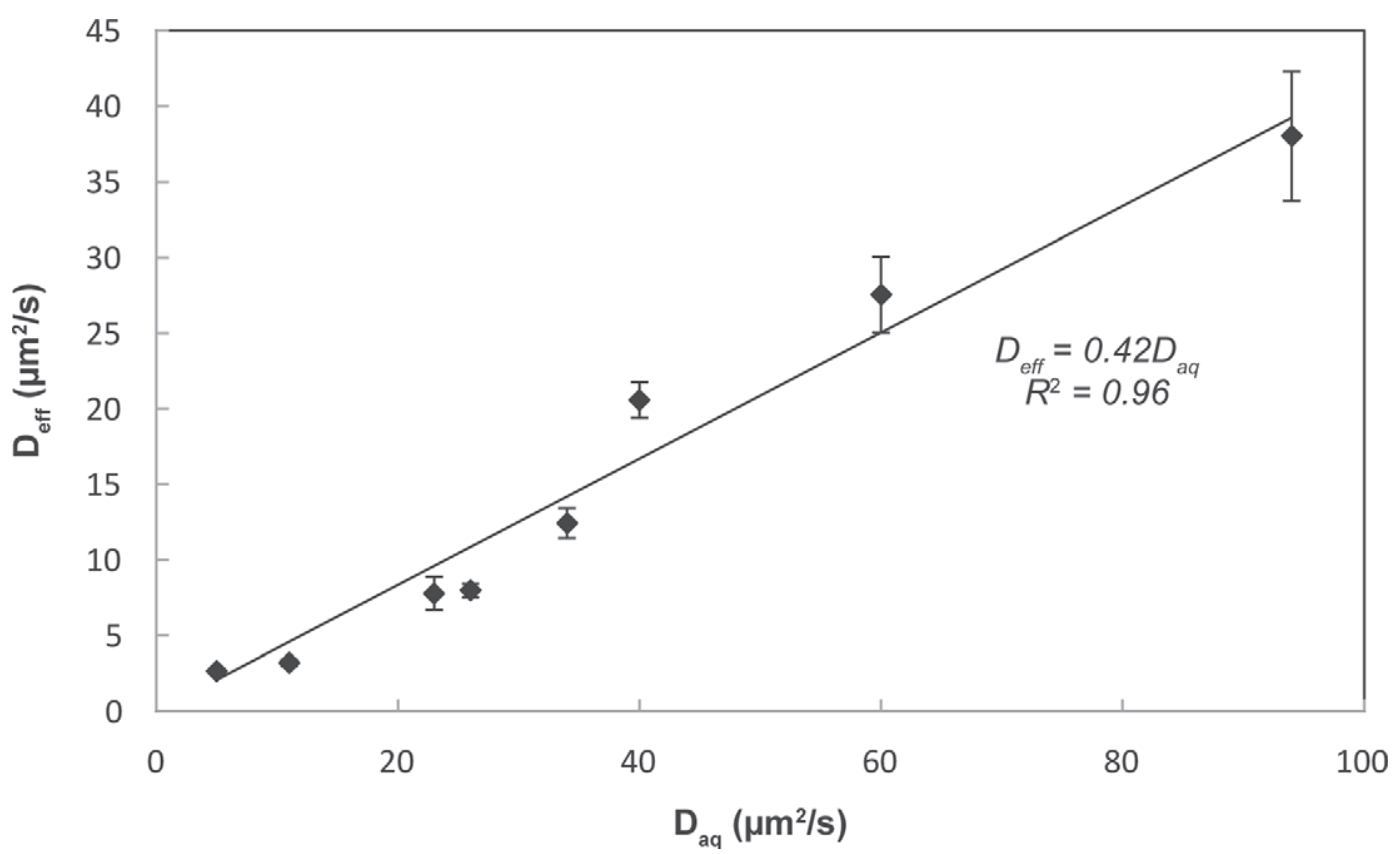

Figure 3. Effective diffusion coefficients for the fluorescein isothiocyanate (FITC)-dextrans in the UF model cheese as a function of the experimental diffusion coefficients in the ultrafiltrate (aqueous phase). $D_{\text {eff }}=$ effective diffusion coefficient; $D_{\text {aq }}=$ diffusion coefficient in the aqueous phase.

the proteins) is probably greater than that hindering the diffusion of the flexible solutes (i.e., the dextrans). However, we concluded that the pore sizes of the UF model cheese were larger than the maximum diameter of the FITC-dextrans studied (diameter of $50 \mathrm{~nm}$ for FITC-D2000), and thus, also larger than the maximum diameter of the proteins studied (diameter of $7 \mathrm{~nm}$ for FITC-BSA). Thus, the assumption must be that the proteins can diffuse through the protein aggregates present in the UF model cheese. The diffusing protein molecules might remain trapped in the pores of protein aggregates for longer than the flexible molecules. The pores of the protein aggregates could sterically hinder the diffusion of the diffusing proteins, affecting the overall diffusion of these solutes. It is important to note that dextran molecules could also diffuse through these aggregates, but this diffusion pathway did not influence overall diffusion when they diffused in the UF model cheese. However, for the protein solutes, their diffusion through the protein aggregates in the matrix could play an important role in their overall diffusion, retarding their movement when they diffused in the UF model cheese compared with the flexible solutes. Therefore, the charge and shape of solute molecules greatly influenced the diffusion ability of the protein solutes in the UF model cheese. As a result, the obstruction model described by Eq. [2] could not be applied to describe diffusion in the model cheese for the rigid solutes (pro- teins), because this mathematical model does not take into account solute-matrix interactions.

\section{CONCLUSIONS}

The effective diffusion coefficients of macromolecules (from $4 \mathrm{kDa}$ to $2 \mathrm{MDa}$ ) in the UF model cheese were successfully investigated using the FRAP technique in

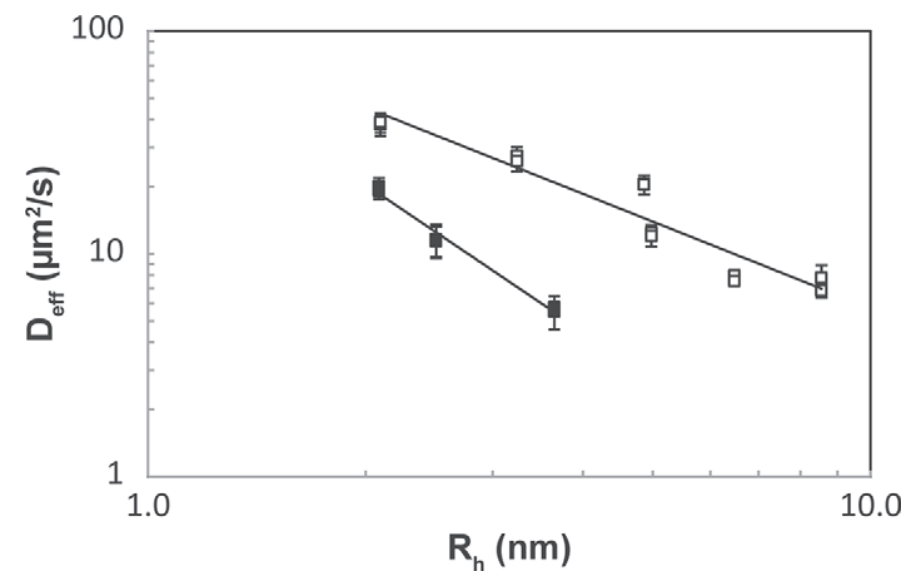

Figure 4. Logarithmic plots of experimental diffusion coefficients of fluorescein isothiocyanate (FITC)-dextrans ( $\square$ ) and FITC-dairy proteins ( $\mathbf{\square})$ in the UF model cheese as a function of their hydrodynamic radius $\left(R_{\mathrm{h}}\right)$. $D_{\text {eff }}=$ effective diffusion coefficient. 
combination with CLSM. The existence of solute-matrix interactions between the model cheese matrix and the FITC-dairy proteins is suggested. The determination and quantification of solute-matrix interactions by other techniques (e.g., fluorescence correlation spectroscopy) is now required for a better understanding of the influence of different physicochemical characteristics of solutes on their diffusion in the UF model cheese. Apart from physicochemical characteristics of the solute molecules (size, shape, and charge), diffusion phenomena will mainly depend on the cheese composition and microstructure. Therefore, to be able to control mass transport in cheese, it will be necessary to understand the limitations of diffusion as a function of the microstructure, composition, and heterogeneity of the product. Further studies are underway in an effort to elucidate the influence of the structure and composition of the matrix on the diffusion of solutes in different model cheese matrices.

\section{ACKNOWLEDGMENTS}

The authors are grateful for the financial support from the Brittany Regional Council and INRA Rennes (France). Furthermore, the authors acknowledge the help received from Pascal Pachot (Stat-plan, Vezinle-Coquet, France) in developing the $\mathrm{R}$ algorithm for modeling the diffusion coefficients.

\section{REFERENCES}

Aly, S., J. Floury, M. H. Famelart, M. N. Madec, D. Dupont, Y. Le Gouar, S. Lortal, and S. Jeanson. 2011. Nisin quantification by ELISA allows the modeling of its apparent diffusion coefficient in model cheeses. J. Agric. Food Chem. 59:9484-9490.

Amsden, B. 1998a. Solute diffusion in hydrogels: Mechanisms and models. Macromolecules 31:8382-8395.

Amsden, B. 1998b. Solute diffusion in hydrogels: An examination of the retardation effect. Polym. Gels Netw. 6:13-43.

Amsden, B. 2002. Modeling solute diffusion in aqueous polymer solutions. Polymer (Guildf.) 43:1623-1630.

Axelrod, D., D. E. Koppel, J. Schlessinger, E. Elson, and W. W. Webb. 1976. Mobility measurement by analysis of fluorescence photobleaching recovery kinetics. Biophys. J. 16:1055-1069.

Babu, S., J. C. Gimel, and T. Nicolai. 2008. Tracer diffusion in colloidal gels. J. Phys. Chem. B 112:743-748.

Balakrishnan, G., T. Nicolai, and D. Durand. 2012. Relation between the gel structure and the mobility of tracers in globular protein gels. J. Colloid Interface Sci. 388:293-299.

Beretta, S., G. Chirico, and G. Baldini. 2000. Short-range interactions of globular proteins at high ionic strengths. Macromolecules 33:8663-8670.

Blonk, J. C. G., and H. Vanaalst. 1993. Confocal scanning light-microscopy in food research. Food Res. Int. 26:297-311.

Bona, E., R. S. Silva, D. Borsato, L. H. Silva, and D. A. S. Fidelis. 2007. Multicomponent diffusion modeling and simulation in Prato cheese salting using brine at rest: The finite element method approach. J. Food Eng. 79:771-778.

Bouchoux, A., G. Gésan-Guiziou, J. Pérez, and B. Cabane. 2010. How to squeeze a sponge: Casein micelles under osmotic stress, a SAXS study. Biophys. J. 99:3754-3762.
Braeckmans, K., L. Peeters, N. N. Sanders, S. C. De Smedt, and J. Demeester. 2003. Three-dimensional fluorescence recovery after photobleaching with the confocal scanning laser microscope. Biophys. J. 85:2240-2252.

Braga, J., J. M. P. Desterro, and M. Carmo-Fonseca. 2004. Intracellular macromolecular mobility measured by fluorescence recovery after photobleaching with confocal laser scanning microscopes. Mol. Biol. Cell 15:4749-4760.

Brocklehurst, T. F., A. R. Mackie, D. C. Steer, and D. R. Wilson, inventors. 1995. Detection of microbial growth. UK Pat. No. 9313052.4

Brocklehurst, T. F., R. B. Piggott, A. C. Smith, and D. C. Steer. 1996. An apparatus for studying the effect of transient temperature on growth of bacteria in a gel matrix. Food Microbiol. 13:109-114.

Cai, L. H., S. Panyukov, and M. Rubinstein. 2011. Mobility of nonsticky nanoparticles in polymer liquids. Macromolecules 44:78537863.

Carrero, G., D. McDonald, E. Crawford, G. de Vries, and M. J. Hendzel. 2003. Using FRAP and mathematical modeling to determine the in vivo kinetics of nuclear proteins. Methods 29:14-28.

Carvajal-Rondanelli, P. A., and T. C. Lanier. 2010. Diffusion of active proteins into fish meat to minimize proteolytic degradation. J. Agric. Food Chem. 58:5300-5307.

Colsenet, R. 2005. Étude par RMN de la diffusion moléculaire: Influence de la structure des protéines laitières à l'état liquide et gélifié. PhD Thesis. Université de Nantes and Cemagref de Rennes, France.

Colsenet, R., F. Mariette, and M. Cambert. 2005a. NMR relaxation and water self-diffusion studies in whey protein solutions and gels. J. Agric. Food Chem. 53:6784-6790.

Colsenet, R., O. Soderman, and F. Mariette. 2005b. Effect of casein concentration in suspensions and gels on poly(ethylene glycol)s NMR self-diffusion measurements. Macromolecules 38:9171-9179.

Colsenet, R., O. Soderman, and F. Mariette. 2005c. Diffusion of polyethyleneglycols in casein solutions and gels as studied by pulsed field gradient NMR. Magn. Reson. Imaging 23:347-348.

Colsenet, R., O. Soderman, and F. O. Mariette. 2006. Pulsed field gradient NMR study of poly(ethylene glycol) diffusion in whey protein solutions and gels. Macromolecules 39:1053-1059.

Croguennoc, P., T. Nicolai, M. E. Kuil, and J. G. Hollander. 2001. Self-diffusion of native proteins and dextran in heat-set globular protein gels. J. Phys. Chem. B 105:5782-5788.

de Gennes, P. G. 1979. Brownian motions of flexible polymer chains. Nature 282:367-370.

Diaz, G., W. Wolf, A. E. Kostaropoulos, and W. E. L. Spiess. 1993. Diffusion of low-molecular compounds in food model systems. J. Food Process. Preserv. 17:437-454.

Fatin-Rouge, N., K. Starchev, and J. Buffle. 2004. Size effects on diffusion processes within agarose gels. Biophys. J. 86:2710-2719.

Favre, E., M. Leonard, A. Laurent, and E. Dellacherie. 2001. Diffusion of polyethyleneglycols in calcium alginate hydrogels. Colloid Surface A 194:197-206.

Ferron-Baumy, C., J. L. Maubois, G. Garric, and J. P. Quiblier. 1991. Coagulation présure du lait et des retentats d'ultrafiltration. Effects de divers traitements thermiques. Lait 71:423-434.

Flory, P. J. 1953. Principles of Polymer Chemistry. Cornell University Press, Ithaca, NY.

Floury, J., S. Jeanson, S. Aly, and S. Lortal. 2010. Determination of the diffusion coefficients of small solutes in cheese: A review. J. Dairy Sci. Technol. 90:477-508.

Floury, J., M. N. Madec, F. Waharte, S. Jeanson, and S. Lortal. 2012. First assessment of diffusion coefficients in model cheese by fluorescence recovery after photobleaching (FRAP). Food Chem. 133:551-556.

Floury, J., O. Rouaud, M. Le Poullennec, and M. H. Famelart. 2009. Reducing salt level in food: Part 2. Modelling salt diffusion in model cheese systems with regards to their composition. Lebenson. Wiss. Technol. 42:1621-1628.

Guinee, T. P. 2004. Salting and the role of salt in cheese. Int. J. Dairy Technol. 57:99-109. 
Hagman, J., N. Loren, and A. M. Hermansson. 2010. Effect of gelatin gelation kinetics on probe diffusion determined by FRAP and rheology. Biomacromolecules 11:3359-3366.

Hermansson, A. M., N. Lorén, and M. Nydén. 2006. The effect of microstructure on solvent and solute diffusion on the micro- and nanolength scales. Pages 79-100 in Water properties of food, pharmaceutical and biological materials. M. P. Buena, J. Welti-Chanes, P. J. Lillford, and H. R. Corti, ed. CRC Press, Boca Raton, FL.

Jeanson, S., J. Chadoeuf, M. N. Madec, S. Aly, J. Floury, T. F. Brocklehurst, and S. Lortal. 2011. Spatial distribution of bacterial colonies in a model cheese. Appl. Environ. Microbiol. 77:1493-1500.

Johansson, L., and J.-E. Löfroth. 1991. Diffusion and interaction in gels and solutions: I. Method. J. Colloid Interf. Sci. 142:116-120.

Johnson, E. M., D. A. Berk, R. K. Jain, and W. M. Deen. 1996. Hindered diffusion in agarose gels: Test of effective medium model. Biophys. J. 70:1017-1023.

Jönsson, B., H. Wennerström, P. G. Nilsson, and P. Linse. 1986. Selfdiffusion of small molecules in colloidal systems. Colloid Polym. Sci. 264:77-88.

Kinsella, J. E., and D. M. Whitehead. 1989. Proteins in whey: Chemical, physical, and functional properties. Adv. Food Nutr. Res. $33: 343-438$

Le Feunteun, S. 2007. Diffusion de sondes moléculaires mesurée par RMN à gradient de champ pulsé: Application à l'étude de l'évolution de la structure des systèmes caséiques au cours de la formation des gels. $\mathrm{PhD}$ Thesis. Université de Nantes and Cemagref de Rennes, France.

Le Feunteun, S., and F. Mariette. 2008. PFG-NMR techniques provide a new tool for continuous investigation of the evolution of the casein gel microstructure after renneting. Macromolecules 41:2071-2078.

Lebrun, L., and G. A. Junter. 1993. Diffusion of sucrose and dextran through agar gel membranes. Enzyme Microb. Technol. 15:10571062.

Lorén, N., M. Nyden, and A. M. Hermansson. 2009. Determination of local diffusion properties in heterogeneous biomaterials. Adv. Colloid Interface Sci. 150:5-15.

Masaro, L., and X. X. Zhu. 1999a. Physical models of diffusion for polymer solutions, gels and solids. Prog. Polym. Sci. 24:731-775.

Masaro, L., and X. X. Zhu. 1999b. Self-diffusion of end-capped oligo(ethylene glycol)s in poly(vinyl alcohol) aqueous solutions and gels. Macromolecules 32:5383-5390.

Masaro, L., X. X. Zhu, and P. M. Macdonald. 1998. Self-diffusion of oligo- and poly(ethylene glycol)s in poly(vinyl alcohol) aqueous solutions as studied by pulsed-gradient NMR spectroscopy. Macromolecules 31:3880-3885.

Matsukawa, S., and I. Ando. 1997. Study of self-diffusion of molecules in a polymer gel by pulsed-gradient spin-echo ${ }^{1} \mathrm{H}$ NMR. 2. Intermolecular hydrogen-bond interaction between the probe polymer and network polymer in N,N-dimethylacrylamide-acrylic acid copolymer gel systems. Macromolecules 30:8310-8313.

McMahon, D. J., and B. S. Oommen. 2008. Supramolecular structure of the casein micelle. J. Dairy Sci. 91:1709-1721.

McSweeney, P. L. H. 2004. Biochemistry of cheese ripening. Int. J. Dairy Technol. 57:127-144.

Messens, W., K. Dewettinck, and A. Huyghebaert. 1999. Transport of sodium chloride and water in Gouda cheese as affected by highpressure brining. Int. Dairy J. 9:569-576.

Morris, H. A., T. P. Guinee, and P. F. Fox. 1985. Salt diffusion in Cheddar cheese. J. Dairy Sci. 68:1851-1858.

Nugent, L. J., and R. K. Jain. 1984. Plasma pharmacokinetics and interstitial diffusion of macromolecules in a capillary bed. Am. J. Physiol. 246:H129-H137.
Pajonk, A. S., R. Saurel, and J. Andrieu. 2003. Experimental study and modeling of effective $\mathrm{NaCl}$ diffusion coefficients values during Emmental cheese brining. J. Food Eng. 60:307-313.

Payet, L., A. Ponton, L. Léger, H. Hervet, J. L. Grossiord, and F. Agnely. 2008. Self-diffusion in chitosan networks: From a gel-gel method to fluorescence recovery after photobleaching by fringe pattern. Macromolecules 41:9376-9381.

Payne, M. R., and K. R. Morison. 1999. A multi-component approach to salt and water diffusion in cheese. Int. Dairy J. 9:887-894.

Perry, P. A., M. A. Fitzgerald, and R. G. Gilbert. 2006. Fluorescence recovery after photobleaching as a probe of diffusion in starch systems. Biomacromolecules 7:521-530.

Pluen, A.. P. A. Netti, R. K. Jain, and D. A. Berk. 1999. Diffusion of macromolecules in agarose gels: Comparison of linear and globular configurations. Biophys. J. 77:542-552.

Prausnitz, M. R., and J. S. Noonan. 1998. Permeability of cornea, sclera, and conjunctiva: A literature analysis for drug delivery to the eye. J. Pharm. Sci. 87:1479-1488.

Saltzman, W. M., M. L. Radomsky, K. J. Whaley, and R. A. Cone. 1994. Antibody diffusion in human cervical mucus. Biophys. J. 66:508-515.

Seiffert, S., and W. Oppermann. 2005. Systematic evaluation of FRAP experiments performed in a confocal laser scanning microscope. J. Microsc. 220:20-30.

Seiffert, S., and W. Oppermann. 2008. Diffusion of linear macromolecules and spherical particles in semidilute polymer solutions and polymer networks. Polymer (Guildf.) 49:4115-4126.

Simal, S., E. S. Sanchez, J. Bon, A. Femenia, and C. Rossello. 2001 Water and salt diffusion during cheese ripening: Effect of the external and internal resistances to mass transfer. J. Food Eng. 48:269-275.

Svanberg, L., L. Ahrné, N. Lorén, and E. Windhab. 2011. Effect of precrystallization process and solid particle addition on microstructure in chocolate model systems. Food Res. Int. 44:1339-1350.

Tao, H., T. P. Lodge, and E. D. von Meerwall. 2000. Diffusivity and viscosity of concentrated hydrogenated polybutadiene solutions. Macromolecules 33:1747-1758.

Ulve, V. M., C. Monnet, F. Valence, J. Fauquant, H. Falentin, and S. Lortal. 2008. RNA extraction from cheese for analysis of in situ gene expression of Lactococcus lactis. J. Appl. Microbiol. 105:1327-1333.

Varzakas, T. H., G. C. Leach, C. J. Israilides, and D. Arapoglou. 2005. Theoretical and experimental approaches towards the determination of solute effective diffusivities in foods. Enzyme Microb. Technol. 37:29-41.

Vaziri, M., H. Abbasi, and A. Mortazavi. 2010. Microstructure and physical properties of Quarg cheese as affected by different heat treatments. J. Food Process. Preserv. 34:2-14.

Waharte, F., K. Steenkeste, R. Briandet, and M. P. Fontaine-Aupart. 2010. Diffusion measurements inside biofilms by image-based fluorescence recovery after photobleaching (FRAP) analysis with a commercial confocal laser scanning microscope. Appl. Environ. Microbiol. 76:5860-5869.

Welti-Chanes, J., H. Mujica-Paz, A. Valdez-Fragoso, and R. LeonCruz. 2003. Fundamentals of mass transport. Pages 3-23 in Transport Phenomena in Food Processing. J. Welti-Chanes, J. F. VélezRuiz, and G. V. Barbosa-Canovas, ed. CRC Press, Boca Raton, FL. 